\title{
Chronic Subdural Hematoma: Pitfalls to Avoid for Better Outcome
}

\author{
Ahmed El Fiki* ${ }^{(0)}$, Ahmed Assem \\ Department of Neurosurgery, Cairo University, Cairo, Egypt \\ Email: *asfiki@yahoo.com
}

How to cite this paper: El Fiki, A. and Assem, A. (2019) Chronic Subdural Hematoma: Pitfalls to Avoid for Better Outcome. Open Journal of Modern Neurosurgery, 9, 419-428.

https://doi.org/10.4236/ojmn.2019.94039

Received: September 5, 2019

Accepted: October 8, 2019

Published: October 11, 2019

Copyright $\odot 2019$ by author(s) and Scientific Research Publishing Inc. This work is licensed under the Creative Commons Attribution International License (CC BY 4.0).

http://creativecommons.org/licenses/by/4.0/

\begin{abstract}
Introduction: Chronic subdural hematoma is one of the commonest intracranial haemorrhages that affect elderly. Headache and focal neurological deficits are among the commonest presentations. It carries excellent prognosis especially when evacuated probably on right timing. Recurrence rate ranging from $8 \%-37 \%$ in literatures, we will highlight tricks during peri-operative period to have better outcome and decrease recurrence. Patients and methods: We operated 45 cases of chronic subdural hematoma in Cairo university emergencyhospital, during the period from November 2016 to December 2017; CT brain was done for all cases; clinical data were reported; burr hole evacuation was the standard technique. Suction drain with mild suction pressure was applied and hospital stay was 3 - 4 days after surgery. Patients were followed up to three months. Results: Forty-five patients were operated with 27 cases $(60 \%)$ having their ages between $5^{\text {th }}$ and $7^{\text {th }}$ decades. Among Twenty-nine males and 16 females, eleven patients (25\%) were confused; headache was observed in 12 patients, weakness in 31 cases (69\%), dysphasia in two cases and two patients were on renal dialysis. Hypertension was associated as a comorbidity in 18 patients, diabetes mellitus in 11 patients, and smoking in 11 patients. Forty-two patients were discharged home within 3 - 4 days; two cases developed small-sized intra-cerebral hematoma, one case of wound infection, and excellent outcome for all cases on three months follow up visit. Conclusions: Chronic subdural hematoma is one of the commonest intra-cranial haemorrhages in elderly with excellent outcome if managed meticulously in right timing. Good control of co-morbidities, insuring slow clearing of hematoma fluid and staged closure technique are factors linked with better outcome. But larger studies are needed.
\end{abstract}

\section{Keywords}

Chronic Subdural Hematoma, Pitfalls, Avoidance 


\section{Introduction}

Pachymeningitis haemorrhagica interna, a term was used by Virchow to name chronic subdural hematoma (CSDH) during the eighteen century (1857). Trauma to bridging veins was later postulated by trotter and changes its name to subdural haemorrhagic cyst [1].

It is one of the commonest intracranial pathologies that give excellent outcomes if managed probably and in the right timing. Longer life expectancy in developing countries had increased the incidence of CSDH [2] [3] [4] [5].

Old people are more exposed to develop CSDH especially after minor trauma due to brain atrophy that decreases the space between the brain and skull from $6 \%$ to $11 \%$ of the intracranial space, leading to stretching of aging fragile cortical veins that can be easily torn with minor trauma [6] [7].

Although trauma is an important factor to develop CSDH; however direct head trauma is absent in up to $30 \%-50 \%$ of the patients. Fall without hitting the head to the ground was reported in almost half of CSDH patients [8] [9].

Other risk factors may include bleeding tendency, epilepsy, alcoholism and cases that may develop low intracranial pressure in conditions like dehydration and renal dialysis [10]

The collected blood will be covered by thin layer of fibrin and fibroblasts forming hematoma membrane on the fourth day up to two weeks. Phagocytes lead to haematoma liquefaction. New fragile vessel formed in the capsule [11].

The osmotic theory claims that the difference between hematoma contents with higher proteins facilitating fluid transfer through the semipermeable membrane from the nearby vessels [12]. It was denied by Wier et al. who proved that hematoma fluid, blood and cerebrospinal fluid CSF have the same osmolality [13].

Recurrent bleeding from abnormally dilated blood vessels in CSDH capsule is nowadays more accepted theory especially with concurrent use of anticoagulation [14].

Ito et al. demonstrated that there is fresh bleeding in $\mathrm{CSDH}$ evacuated fluid reaching from $2 \%-28 \%$ of cases that were injected $51 \mathrm{cr}$-labled RBCs intravenously 6 - 24 hours before evacuation [15].

We will discuss our experience in $\mathrm{CSDH}$ cases with highlight on pitfalls to avoid recurrence.

\section{Methods}

During the period from November 2016 to December 2017 we operated 45 cases of CSDH in emergency neurosurgery unit, Cairo university hospitals, Egypt.

Computerized topography was done for all cases, and after confirming the diagnosis and indication for surgery, preparation and shifting to operating room was done (Figure 1). Our department ethical committee approval was taken for our study. 


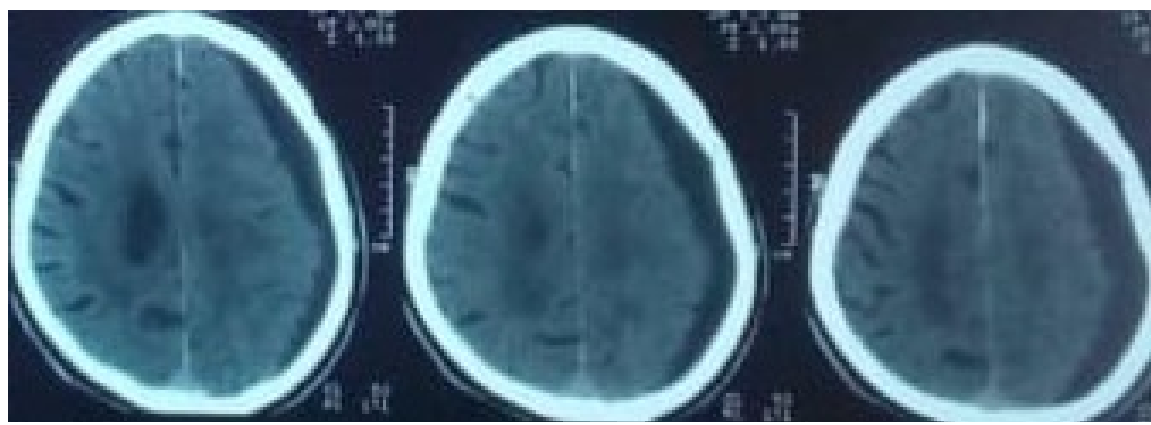

Figure 1. CT brain showing hypodense left fronto-patrietal chronic subdural hematoma.

\subsection{Pre-Operative Tricks}

Whenever possible, pre-operative assessment and control of associated co-morbidity are important for better outcome especially coagulopathy, renal impairment or diabetes mellitus.

\subsection{Operative Tricks}

- We usually do our operation under general anaesthesia expect if associated co-morbidity that carries high mortality risk, so we prefer local anaesthesia and sedation only.

- Burr hole localization depends on site of maximum thickness, whether intra-sac septae are present or not (avoid putting both burr holes in front of septum).

- We make skin incision vertical over superior temporal line in both anterior and posterior burr holes just in case we need to extend surgery to full craniotomy it will be easier to extend skin incision between both vertical limbs.

- Size of the burr hole is $1 \mathrm{~cm}$ only and no need to be larger.

- During opening of coagulated dura, it should be controlled and covered by cottonoid to avoid sudden decompression with the possibility to develop intracerebral hematoma.

- Subdural saline solution wash in all directions should be continued in both burr holes till fluid come clear from other side.

- We didn't try to expand the brain by intrathecal injection of normal saline in any of our cases.

- Small subgaleal pocket in front of anterior burr hole to accommodate suction drain (size 12 - 14 fr) over both burr holes extra-cranially and passes away and above the posterior burr hole.

- Staged closure technique: closure in layers without covering of the dural opening to facilitate any fluid in subdural space to be drained. We start closing posterior wound first and ensuring that wash fluid between sutures to come through the drain and anterior wound clearly then closure of anterior wound is done. This step helps to avoid post-operative peumocephaly.

- Mild suction power is applied, and suction drain is unlocked after full recovery from anaesthesia. 


\subsection{Post-Operative Tricks}

- Intravenous fluid for 1 - 2 days (ringer or glucose 5\% solution).

- Prophylactic anticonvulsants were given for one month even if seizures were not the presenting symptom.

- Head elevation up to 30 degrees may be applied.

- Early ambulation and physiotherapy.

- Continuous correction of co-morbidities.

- Follow up was done using Glasgow outcome scale score (GOS) [16].

\section{Results}

We operated forty-five cases of CSDH including 29 males (65\%) and 16 females $(35 \%)$, twenty-seven cases $(60 \%)$ with ages lies in $5^{\text {th }}$ to $7^{\text {th }}$ decade, we have three cases over 80 years.

Thirty-four patients (75\%) were fully conscious at time of presentation while eleven patients (25\%) were confused (GCS 13 - 14) (Figure 2).

Headache was the presenting symptom in 12 cases, weakness was clinically observed in 31 patients (69\%) and it was almost equally affecting both sides of the body. Two cases were dysphasic, and one patient was on renal dialysis.

Minor head trauma was remembered in 17 patients while only eight patients reported falling with no head trauma. Another 20 patients (45\%) gives no history of any head trauma or falls.

Regarding co-morbidity 18 (40\%) patients were hypertensive, 11 patients were diabetics, five hepatic patients, 11 cases were smokers, two cardiac, two renal patients (one presenting during dialysis session). And three cases were on anticoagulants (Figure 3 ).

We found that hematoma was hypodense in 25 cases (55\%), isodense in 5 cases (11\%), mixed density in 10 cases (22\%) and hyperdense in 5 cases (Figure 4).

Midline shift was $1-2 \mathrm{~cm}$ in twenty-nine cases (65\%), more than $3 \mathrm{~cm}$ in one case and the rest of cases didn't show midline shift or it was less than $1 \mathrm{~cm}$.

Tirty three patients (74\%) are with hematoma thickness $3-4 \mathrm{~cm}$, eleven patients (24\%) with hematoma thickness $2 \mathrm{~cm}$ and one case with $5 \mathrm{~cm}$ hematoma thickness (Figure 5).

\section{Presenting GCS}

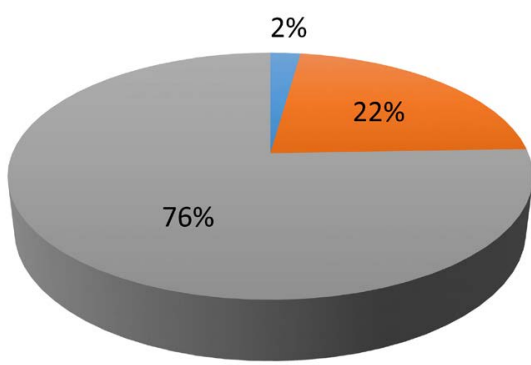

$\square 13 / 15(2 \%)-14 / 15(22 \%)-15 / 15(76 \%)$

Figure 2. Glasgow coma scale on presentation (percentage and number of cases). 


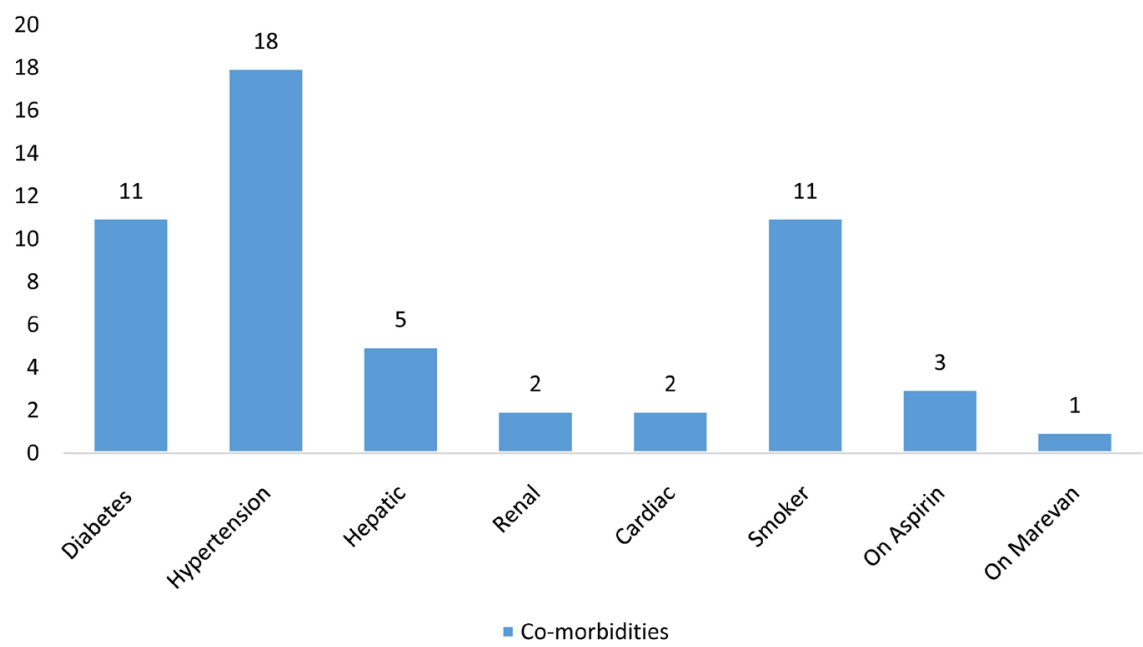

Figure 3. Number of co-morbidities associated our cases.

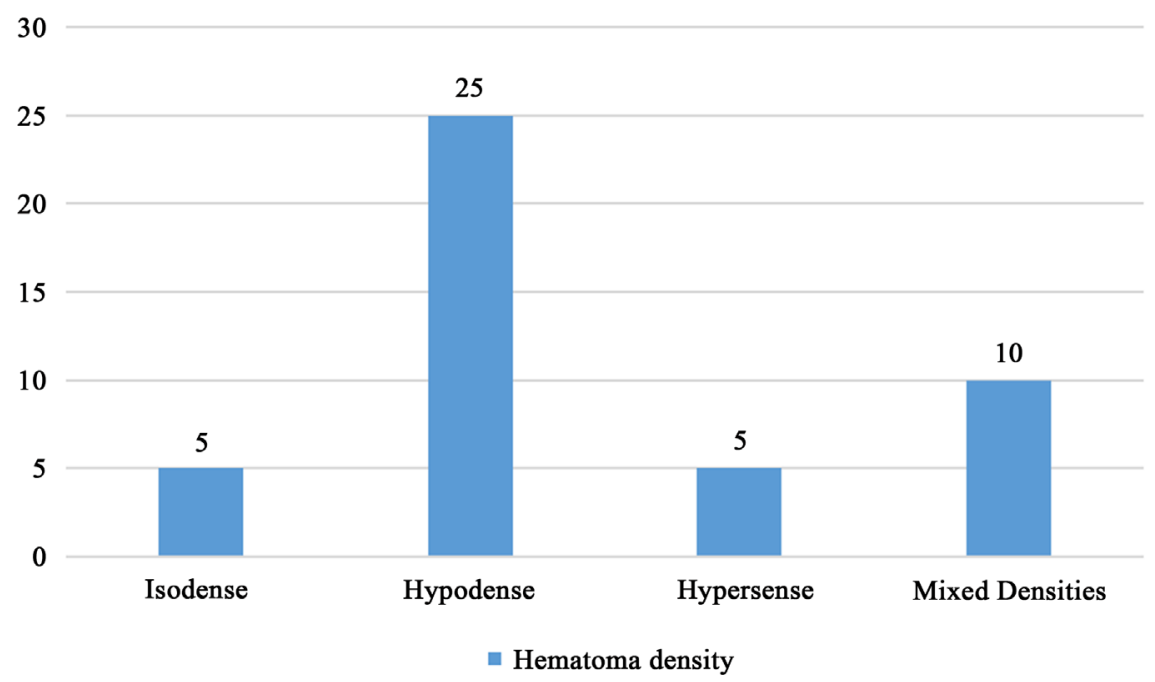

Figure 4. Density of chronic subdural hematoma in pre-operative CT (number of cases).

Hematoma Thickness

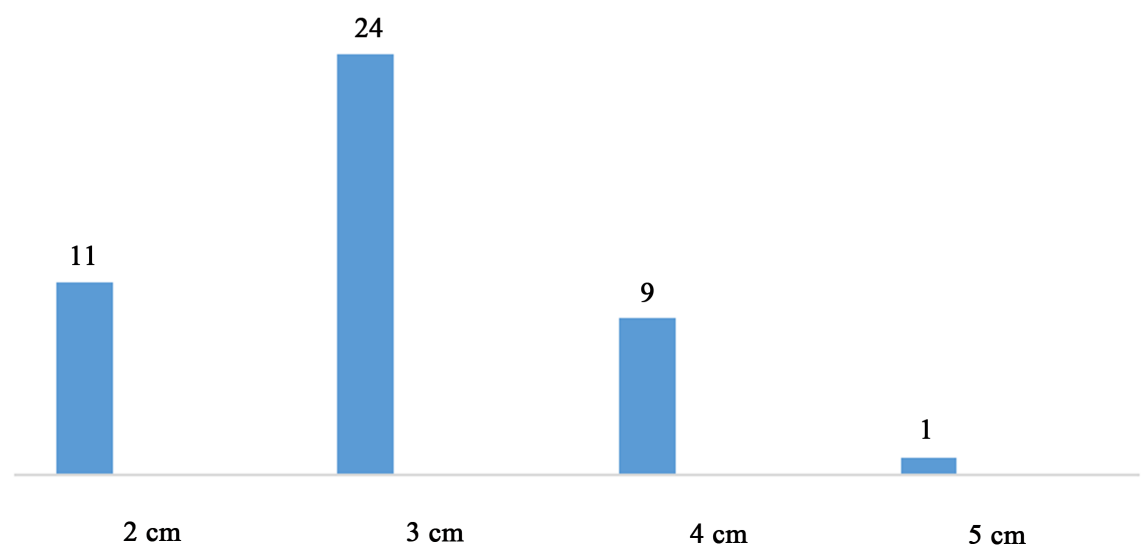

Figure 5. Number of cases and thickness of hematoma. 
Thirty-one patients were harbouring their hematoma all over the cerebral hemisphere while only 14 patients developed localized (frontal or parietal) hematoma.

Smooth recovery and discharge within 3 - 4 days occurred in 42 cases (94\%), follow up CT brain was done for all cases two days after surgery to check if there is any serious new finding; only two cases developed post-operative intra-cerebral hematoma that was managed conservatively.

One patient developed wound infection which also was treated with antibiotic course and tight DM control and patient was discharged after one week.

None of our cases develop tension pneumocephaly or seizures post-operative

During the first month follow up visit; six cases develop re-appearance of symptoms (four cases with weakness and two cases of headache) and by repeating CT scan, re-collection and second exploration were done.

Follow up visit after three months was done. Excellent recovery was achieved for all cases including the recollected cases. And the patients presenting with weakness resumed normal motor power.

\section{Discussion}

Chronic subdural hematoma is one of commonest types of intracranial haemorrhages especially in old age, recent advances in diagnostic investigations and surgical modalities facilitating dealing with the hematoma. But there is also some debate regarding the best management strategy [3] [17] [18] [19] [20] [21].

Simple evacuation by burr holes and putting a closed drainage system gives excellent results although it can be followed by recurrence which if repeated, it is preferably to be re-operated again first by re-exploration of burr holes and later by craniotomy [22] [23] [24] [25] [26]. Some authors believe that slow sucking of subdural fluid without injuring the inner membrane is the golden goal for any intervention for CSDH cases regardless of the surgical technique [27] [28] [29] [30].

Computerized topography (CT) before surgery can give some information about the prognosis, hyper and mixed density of the hematoma may be linked with higher recurrence rate [17] [19] [31] [32], especially if associated with intra-sac septae which may be explained by the presence of excess exudates, higher protein levels and fibrinolytics in fresh blood leading to more bleeding [33] [34] [35] and this like what we found that four of our recurrent cases were hyper and mixed density and with septae, while the last two cases were hypodense in preoperative CT scan. And this was strongly related to what was found by many authors [17] [32] [36] [37] [38] [39].

So, we recommend continuous washing until clear fluid is coming out through the other burr hole to wash as much as we can from these exudates and fibrinolytics to avoid recurrence especially in hyper or mixed density CSDH.

Residual fluid in the subdural space is a common finding in about $80 \%$ of cases in postoperative CT brain and usually asymptomatic, but real recurrence 
usually with recurred clinical complaints which often start from $4^{\text {th }}$ day up to four weeks has been observed in $8 \%-37 \%$ of operated cases [7]. Our recurrence rate is similar to what was reported in literature (14\%).

The CSDH thickness in pre-operative CT scan may give an impression about outcome prediction. the more the thickness, the more expected bad elasticity of the brain especially in old age and poor expansion with higher possibility of recurrence and pneumocephaly to develop [2] [18] [40].

Four of our recurrent cases were with hematoma thickness from 3 to $4 \mathrm{~cm}$ with age in $5^{\text {th }}$ and $6^{\text {th }}$ decades which is like what was expected by other authors. We don't have post-operative tension peumocephaly in our cases and this may be due to the closure technique mentioned before.

Morbidity and mortality differ significantly in literature in cases of CSDH after surgery but in general it may reach $16 \%$ and $6.5 \%$ respectively [41]. In our study six patients developed recollection (13\%) and were re-operated, we had no mortality and all neurological deficits resolved on the three months follow-up visit.

Our study has some limitation include small study number and focusing only on one surgical technique (burr hole evacuation) but further studies should consider collaboration with other centres performing different modalities for CSDH management.

\section{Conclusion}

Chronic subdural hematoma is one of the commonest intracranial haemorrhages in elderly that carries excellent outcome after evacuation. Peri-operative good control of co-morbidities, insuring slow clearing of hematoma fluid and staged closure technique are factors linked with better outcome. But larger studies are needed.

\section{Conflicts of Interest}

The authors declare no conflicts of interest regarding the publication of this paper.

\section{References}

[1] Fogelholm, R. and Waltimo, O. (1975) Epidemiology of Chronic Subdural Haematoma. Acta Neurochirurgica, 32, 247-250. https://doi.org/10.1007/BF01405457

[2] Gorelick, P.B. and Weisman, S.M. (2005) Risk of Hemorrhagic Stroke with Aspirin Use: Anupdate. Stroke, 36, 1801-1807. https://doi.org/10.1161/01.STR.0000174189.81153.85

[3] Mori, K. and Maeda, M. (2001) Surgical Treatment of Chronic Subdural Hematoma in 500 Consecutive Cases: Clinical Characteristics, Surgical Outcome, Complications, and Recurrence Rate. Neurologia Medico-Chirurgica (Tokyo), 41, 371-381. https://doi.org/10.2176/nmc.41.371

[4] Spallone, A., Giuffrè, R., Gagliardi, F.M. and Vagnozzi, R. (1989) Chronic Subdural Hematomain Extremely Aged Patients. European Neurology, 29, 18-22. 
https://doi.org/10.1159/000116370

[5] Zingale, A., Albanese, V., Romano, A., Distefano, G. and Chiaramonte, J. (1997) Traumaticchronic Subdural Hematoma over 80 Years. A Preliminary Prospective Study. Journal of Neurosurgical Sciences, 41, 169-173.

[6] Ellis, G.L. (1990) Subdural Haematoma in the Elderly. Emergency Medicine Clinics of North America, 8, 281-294.

[7] Traynelis, V.C. (1991) Chronic Subdural Haematoma in the Elderly. Clinics in Geriatric Medicine, 7, 583-598. https://doi.org/10.1016/S0749-0690(18)30540-8

[8] Feldman, R.G., Pincus, J.H. and McEntee, W.J. (1963) Cerebrovascular Accident Orsubdural Fluid Collection? Archives of Internal Medicine, 112, 966-976. https://doi.org/10.1001/archinte.1963.03860060178020

[9] Rozzelle, C.J., Wofford, J.L. and Branch, C.L. (1995) Predictors of Hospital Mortality Inolder Patients with Subdural Haematoma. Journal of the American Geriatrics Society, 43, 240-244. https://doi.org/10.1111/j.1532-5415.1995.tb07329.x

[10] Jones, S. and Kafetz, K. (1999) A Prospective Study of Chronic Subdural Haematomasin Elderly Patients. Age Ageing, 28, 519-521. https://doi.org/10.1093/ageing/28.6.519

[11] Munro, D. and Merritt, H.H. (1936) Surgical Pathology of Subdural Haematoma: Based on a Study of One Hundred and Five Cases. Archives of Neurology \& Psychiatry, 35, 64-78. https://doi.org/10.1001/archneurpsyc.1936.02260010074005

[12] Gardner, W.J. (1932) Traumatic Subdural Haematoma with Particular Referenceto the Latent Interval. Archives of Neurology \& Psychiatry, 27, 847-858. https://doi.org/10.1001/archneurpsyc.1932.02230160088009

[13] Weir, B. (1971) The Osmolality of Subdural Haematoma Fluid. Journal of Neurosurgery, 34, 528-533. https://doi.org/10.3171/jns.1971.34.4.0528

[14] Sato, S. and Suzuki, J. (1975) Ultrastructural Observations of the Capsule of Chronicsubdural Haematoma in Various Clinical Stages. Journal of Neurosurgery, 43, 569-578. https://doi.org/10.3171/jns.1975.43.5.0569

[15] Ito, H., Yamamoto, S., Saito, K., et al. (1987) Quantitative Estimation of Haemorrhage in Chronic Subdural Haematoma Using the 51Cr Erythrocyte Labelling Method. Journal of Neurosurgery, 66, 862-864.

https://doi.org/10.3171/jns.1987.66.6.0862

[16] Jennett, B. and Bond, M. (1975) Assessment of Outcome after Severe Brain Damage. Apractical Scale. The Lancet, 1, 480-484.

https://doi.org/10.1016/S0140-6736(75)92830-5

[17] Amirjamshidi, A., Abouzari, M., Eftekhar, B., Rashidi, A., Rezaii, J., Esfandiari, K., et al. (2007) Outcomes and Recurrence Rates in Chronic Subdural Haematoma. British Journal of Neurosurgery, 21, 272-275. https://doi.org/10.1080/02688690701272232

[18] Nakaguchi, H., Tanishima, T. and Yoshimasu, N. (2000) Relationship between Drainage Catheter Location and Postoperative Recurrence of Chronic Subduralhematoma after Burr-Hole Irrigation and Closed-System Drainage. Journal of Neurosurgery, 93, 791-795. https://doi.org/10.3171/jns.2000.93.5.0791

[19] Okada, Y., Akai, T., Okamoto, K., Iida, T., Takata, H. and Iizuka, H. (2002) A Comparative Study of the Treatment of Chronic Subdural Hematoma-Burr Hole Drainage versus Burr Hole Irrigation. Surgical Neurology, 57, 405-409. https://doi.org/10.1016/S0090-3019(02)00720-6

[20] Ramachandran, R. and Hegde, T. (2007) Chronic Subdural Hematomas-Causes of 
Morbidity and Mortality. Surgical Neurology, 67, 367-372. https://doi.org/10.1016/j.surneu.2006.07.022

[21] Santarius, T., Lawton, R., Kirkpatrick, P.J. and Hutchinson, P.J. (2008) The Management of Primary Chronic Subdural Haematoma: A Questionnaire Survey of Practice in the United Kingdom and the Republic of Ireland. British Journal of Neurosurgery, 22, 529-534. https://doi.org/10.1080/02688690802195381

[22] Ernestus, R.I., Beldzinski, P., Lanfermann, H. and Klug, N. (1997) Chronic Subdural Hematoma: Surgical Treatment and Outcome in 104 Patients. Surgical Neurology, 48, 220-225. https://doi.org/10.1016/S0090-3019(97)80031-6

[23] Gonugunta, V. and Buxton, N. (2001) Warfarin and Chronic Subdural Haematomas. British Journal of Neurosurgery, 15, 514-517. https://doi.org/10.1080/02688690120097822

[24] Markwalder, T.M., Steinsiepe, K.F., Rohner, M., Reichenbach, W. and Markwalder, H. (1981) The Course of Chronic Subdural Hematomas after Burr-Hole Craniostomy and Closed-System Drainage. Journal of Neurosurgery, 55, 390-396. https://doi.org/10.3171/jns.1981.55.3.0390

[25] Markwalder, T.M. (1981) Chronic Subdural Hematomas: A Review. Journal of Neurosurgery, 54, 637-645. https://doi.org/10.3171/jns.1981.54.5.0637

[26] Tabaddor, K. and Shulmon, K. (1977) Definitive Treatment of Chronic Subdural Hematomaby Twist-Drill Craniostomy and Closed-System Drainage. Journal of Neurosurgery, 46, 220-226. https://doi.org/10.3171/jns.1977.46.2.0220

[27] Lee, G.Y., Oh, C.H., Shim, Y.S., Yoon, S.H., Park, H.C., Park, C.O., et al. (2013) Comparison of Drainage Volume of Chronic Subdural Hematoma According to Drainage Catheter Type. Yonsei Medical Journal, 54, 1091-1097.

https://doi.org/10.3349/ymj.2013.54.5.1091

[28] Rodziewicz, G.S. and Chuang, W.C. (1995) Endoscopic Removal of Organized Chronic Subdural Hematoma. Surgical Neurology, 43, 569-572. https://doi.org/10.1016/0090-3019(95)00005-4

[29] Weigel, R., Schmiedek, P. and Krauss, J.K. (2003) Outcome of Contemporary Surgery for Chronic Subdural Haematoma: Evidence Based Review. Journal of Neurology, Neurosurgery, and Psychiatry, 74, 937-943. https://doi.org/10.1136/jnnp.74.7.937

[30] Weir, B. and Gordon, P. (1983) Factors Affecting Coagulation: Fibrinolysis in Chronic Subdural Fluid Collections. Journal of Neurosurgery, 58, 242-245. https://doi.org/10.3171/jns.1983.58.2.0242

[31] Lee, K.S., Bae, W.K., Doh, J.W., Bae, H.G. and Yun, I.G. (1998) Origin of Chronic Subdural Haematoma and Relation to Traumatic Subdural Lesions. Brain Injury, 12, 901-910. https://doi.org/10.1080/026990598121972

[32] Oishi, M., Toyama, M., Tamatani, S., Kitazawa, T. and Saito, M. (2001) Clinical Factors of Recurrent Chronic Subdural Hematoma. Neurologia Medico-Chirurgica (Tokyo), 41, 382-386. https://doi.org/10.2176/nmc.41.382

[33] Fujisawa, H., Nomura, S., Tsuchida, E. and Ito, H. (1998) Serum Protein Exudation in Chronic Subdural Haematomas: A Mechanism for Haematoma Enlargement? Acta Neurochirurgica (Wien), 140, 161-165. https://doi.org/10.1007/s007010050077

[34] Nakaguchi, H., Tanishima, T. and Yoshimasu, N. (2001) Factors in the Natural History of Chronic Subdural Hematomas that Influence Their Postoperative Recurrence. Journal of Neurosurgery, 95, 256-262. https://doi.org/10.3171/jns.2001.95.2.0256 
[35] Tokmak, M., Iplikcioglu, A.C., Bek, S., Gökduman, C.A. and Erdal, M. (2007) The Role of Exudation in Chronic Subdural Hematomas. Journal of Neurosurgery, 107, 290-295. https://doi.org/10.3171/JNS-07/08/0290

[36] Delgado, P.D., Cogolludo, F.J., Mateo, O., Cancela, P., García, R. and Carrillo, R. (2000) Early Prognosis in Chronic Subdural Hematomas. Multivariate Analysis of 137 Cases. Revista de Neurología, 30, 811-817. https://doi.org/10.33588/rn.3009.99531

[37] Kim, H.Y., Kwon, S.C., Kim, T.H., Shin, H.S., Hwang, Y.S. and Park, S.K. (2005) Analysis of Management According to CT Findings in Chronic Subdural Hematoma. Journal of Korean Neurosurgical Society, 37, 96-100.

[38] Ko, B.S., Lee, J.K., Seo, B.R., Moon, S.J., Kim, J.H. and Kim, S.H. (2008) Clinical Analysis of Risk Factors Related to Recurrent Chronic Subdural Hematoma. Journal of Korean Neurosurgical Society, 43, 11-15.

https://doi.org/10.3340/jkns.2008.43.1.11

[39] Kong, W.K., Kim, B.C., Cho, K.T. and Hong, S.K. (2012) Factors Affecting Postoperative Recurrence of Chronic Subdural Hematoma. Korean Journal of Neurotrauma, 8, 122-127. https://doi.org/10.13004/kjnt.2012.8.2.122

[40] Sundstrom, T., Helland, C.A., Aarhus, M. and Wester, K. (2011) What Is the Pressure in Chronic Subdural Hematomas? A Prospective, Population-Based Study. Journal of Neurotrauma, 29, 137-142. https://doi.org/10.1089/neu.2011.1776

[41] Van Havenberg, T., van Calenbergh, F., Goffin, J., et al. (1996) Outcome of Chronic Subdural Haematoma: Analysis of Prognostic Factors. British Journal of Neurosurgery, 10, 35-39. https://doi.org/10.1080/02688699650040502 